\title{
THE EFFECT OF PERSON-ENVIRONMENT FIT ON PUBLIC SERVANT INTEGRITY AND PERFORMANCE: INVESTIGATING THE MODERATING ROLE OF PUBLIC SERVICE MOTIVATION
}

\author{
Sangeetha Tannimalay ${ }^{1}$, Noor Fareen Abdul Rahim 1,*, Hong Meen Chee ${ }^{1}$ \\ ${ }^{1}$ Graduate School of Business, Universiti Sains Malaysia, 11800 Pulau Pinang, Malaysia
}

\begin{abstract}
Individual performance is measured by a person's contribution to attaining this objective, whereas public organisation performance is measured by goals achieved in accordance with its mission statements. Positive individual behaviour is important for positive life outcomes, such as professional ethics. Individuals with strong integrity between their psychological (spiritual) and physical (physical) functions are one of the determinants of individual performance in organisations. Integrity is a promise to do everything in line with right and ethical principles, as well as values and standards, and there is consistency in continuing to make these commitments in every scenario without seeing any chance or coercion to break them. Individual integrity and performance are strongly influenced by the person-environment fit (person-job fit and personorganization fit). Due to the several corruption cases in Malaysia, the impacts of personenvironment fit (person-job fit and person-organization fit) on individual integrity and performance of public sector personnel are investigated in this study. The suggested model was tested using partial least squares on a sample of 214 public sector employees in Penang. Integrity and individual performance is positively influenced by both person-job fit and person-organization fit, with personorganization fit having a stronger effect. Furthermore, the moderating effects of Public Service Motivation in the relationship between person-environment fit and the integrity and individual performance are not significant. As a result, it is critical to design strategies and implement suitable organisational environments in order to successfully raise the integrity and performance levels of public sector employees.
\end{abstract}

ARTICLE HISTORY

Received: 15-7-2021

Revised: 21-8-2021

Accepted: 18-10-2021

KEYWORDS

Public sector

Individual Performance

Person-job fit

Person-organisation fit

\section{INTRODUCTION}

Individual performance is a requirement for professional advancement as great performers get promoted sooner and have better career alternatives (Sonnentag \& Frese, 2002). From a practical sense, individual performance is what organisations try to optimise and improve. The study of employee performance is vital in the field of human resource management. The Malaysian Government has made numerous attempts to develop a band of an excellent and energetic workforce capable of reaching the administration's expectations and the clientele in the public sector (Johari \& Yahya, 2016). In the present situation where the government emphasises the human model of the country in terms of intellectual knowledge, competence and skills, integrity also plays a crucial role as a component in enhancing the robustness of the country's performance model. Integrity is a contributor to acknowledging lives enriched by work and relationships (Sani, Endin, Masrek, Sahid, Baba \& Kamis, 2016). Mahdavikhou, Hossein, Moez, Khotanlou, \& Karami (2014), based on Iranian culture, indicated that moral intelligence among employees such as integrity and accountability could create a chain effect to ethical thinking and decision making and sequentially adds to higher job performance.

Nonetheless, it is significant that several converging variables contribute to the desire to be good public servants. First, goals achievement measures a public organisation's performance per its mission statements, whereas individual performance is defined as a person's contribution to achieving this mission. Second, public servant employees are receptive to whether their jobs were acceptable and meaningful (Grindle \& Hilderbrand, 1995). Third, a proud public worker is defined as someone who works honourably, conscientiously, and with dedication and uses his or her education, knowledge, experience, and professional ethics to reach this state (Vermeeren \& van Geest, 2012). As a result, employees with high moral intelligence are said to be constantly vigilant about their work. They do so because they share the company's goals and believe that achieving those goals is part of their responsibility (Salas-Vallina, Alegre, LopezCabrales, 2021). Finally, their urge to contribute to the firm is only to the degree they believe their talents and integrity are leveraged to carry out significant duties.

It raises another critical question: is the person hired to fit the available positions or fit their abilities? For the most part, it appears that the first option is correct for public servants. According to the person-environment fit (PE fit) theory (Kristof-Brown et al., 2005), performance is controlled by the combination of human attributes and institutional setting. 
There are several different sorts of fits that can be identified from one another. The most researched fit categories are person-job fit (PJ fit) and person-organisation fit (PO fit). They are thought to play the most crucial role in influencing behavioural outcomes (Kristof-Brown et al., 2005; Lauver \& Kristof-Brown, 2001; Muchinsky \& Monahan, 1987). Previous research has looked at how perceived PO and PJ fit mediate the association between personal attributes and a variety of work outcomes (Gul, Usman, Liu, Rehman, \& Jebran, 2018; Ryu, 2017; M.Vogel \& C.Feldman, 2009; Cable \& DeRue, 2002; Saks \& Ashforth, 1997; Cable \& Judge, 1996). Only a few research have simultaneously evaluated numerous categories of fit (Hoffman \& Woehr, 2006); nonetheless, insights into the relative relevance of the PJ and PO fits are restricted (Kristof-Brown, Zimmerman \& Johnson, 2005). As a result, the relative roles of these two fits appear to be equivocal. (Vandenabeele, Loon, \& Leisink, 2017). One study looked at the roles of PJ and PO fits in the relationship between PSM and job choice and found that PJ fit was more significant than PO fit (Christensen \& Wright, 2011). Apart from its popularity, the fit concept is rarely used in the public or non-profit sectors, according to Stejin (2008).

Besides the PE fit, another area that is most explored to identify the driving elements behind the performance of public sector employees in the Public Service Motivation (PSM). A survey of the past PSM studies connected to the PE-fit theory shows that they concentrated on studying direct perceptions of the fit with the job or organisation (Bright, 2007; Wright \& Pandey, 2008). These studies are instrumental in showing if a fit with the job or organisation matters but cannot demonstrate how particular settings PSM has a positive relationship with integrity and individual performance or otherwise. In recent years, new research commonly integrate PSM as an intervening variable alongside other variables of interest, indicating that scholars steadily incorporate PSM into the field's knowledge base. (Ritz, Brewer \& Neumann, 2016). The studies on PSM have included a form of fit based on what appears most pertinent for employees with high PSM. For example, Bright (2007) emphasised PO fit since they predicted the organisation's principles to be crucial for a public service-oriented employee. Similarly, Bellé (2012), Leisink \& Steijn (2009) focused on the PJ fit because they predicted that employees with PSM would desire to conduct professions contributing to society. The subject of PSM is rich and deserves more significant examination, particularly in underdeveloped nations, where there is increased interest in motivation but relatively little empirical research to date (Robinson, 2015).

There are three categories of corruption in the public sector, according to Hashim (2017). To begin with, great corruption refers to the political or administrative elite stealing or misappropriating a considerable amount of resources and/or public funds. On the other hand, petty corruption is defined as the abuse of power by medium and low-level government officials in providing or delivering public goods and/or services. Third, state capture/influence peddling occurs when public officials and/or politicians collaborate with commercial groups to achieve common goals. According to the Malaysian Anti-Corruption Commission (MACC), between 2015 and October 2020, 2,607 civil officials were arrested for corruption, according to Malaysian Anti-Corruption Commission (MACC). According to MACC Deputy Chief Commissioner (Prevention) Datuk Seri Shamshun Baharin Mohd Jamil, the implementing group had the most arrests $(1,884)$, followed by the management and professional groups (658) and then the rest of the MACC officers (Bernama, 2020). An empirical examination of the existing Malaysian landscape is also required to provide scholars and practitioners with some insight into the local setting. The Malaysian government employs 1.7 million people in various positions (Parliament of Malaysia, 2019). When we look at the structure more closely, we can see that the functions are often different. Finding the perfect person for every job opening in the public sector is nearly impossible. How can they perform better, and how can this be influenced? Effective public service delivery requires strategic talent management and transformation of public servants' mentality to think, act and respond according to the evolving socioeconomic and technological landscape. Malaysia is also actively transforming its public sector to be more agile, honest, transparent, and efficient. It is evident with the allocation of budget and specific strategies under the five year Malaysia Plan. Under the 11th Malaysia Plan, 2016-2020, various measures were implemented to improve talent management in the public sector, including talent pipeline, work motivations, capacity, and competency building.

Nonetheless, comprehensive measures addressing customised performance management and talent pipelines have yet to be implemented. The Federal Government Development Allocation for public service reform was RM 6,632 million (7.5 per cent) of the total allocation of RM88 320 million between 2016 and 2017. The allocation of RM 6,592 million was used to implement various programmes, accounting for $99.4 \%$. Training for serving officers, study leave with a scholarship programme, recognising subject matter specialists, and promoting fast track officers were examples of extrinsic motivation activities (Vallerand, 1997; Ministry of Economic Affairs, 2018).

The 11th Malaysia Plan's mid-term review was completed in 2018, shortly after the new government took office (Ministry of Economic Affairs, 2018). The new government has emphasised the public sector to reform governance and improve public service efficiency. According to one plan, intensive efforts must be made to instil noble, ethical principles and integrity among public officials to increase performance and develop good work culture and integrity. Ethics is unquestionably important because it can lead to individual or organisational failure and societal failure, and a country's destruction. It would result in a lack of trustworthiness in an individual, a tarnished reputation for an organisation, and a deterrent to investors from investing in a country because they fear a level playing field. In the long run, a lack of ethics can negatively affect the economy and society (Haron, Jamil \& Ramli, 2020).

To do so, the Public Service Department, in collaboration with all ministries and agencies, is implementing four main initiatives: improving ethics and values programmes; evaluating the integrity level of organisations and individuals using proper integrity assessment tools; and continuously instilling noble values through existing public service initiatives such as the 12 Pillars (Tonggak 12) (Ministry of Economic Affairs, 2018). Based on the activities mentioned, it is clear that the government is working to improve public sector employees' intrinsic motivation (Vallerand, 1997). As a result, it's vital to double-check that money set aside to reform the public sector are being used wisely. More importantly, according 
to the same study, efforts and techniques to ensure that the public sector supports the government's aims must be strengthened. Citizens' greater understanding has resulted in increased and higher expectations of quality services and honesty from government officials, who are held accountable for their outcomes. Despite a large body of literature on PE fit and work outcomes, there is limited study in the public sector on the relationship between PJ fit and PO fit regarding individual integrity and performance. To better understand the function of intrinsic motivation among public workers, examining academic studies on this topic is also required. As a result, this research will focus on the relationship between PE Fit (PJ Fit and PO Fit) and public servant integrity and performance, with PSM being proposed as a moderator in this relationship. Moving forward will be aided by a survey that will reflect the current perspective of Malaysian public servants. This study aims to close these gaps by putting the proposed conceptual model to the test and adding to the body of knowledge on the subject.

\section{RELATED WORK}

\section{Integrity and Employee Performance in Public Sector}

Ethics is concerned with the larger moral picture, whereas integrity focuses on particular traits (Haron, Jamil \& Ramli, 2020). Integrity is a good personality quality that includes honour, honesty, righteousness, and the absence of corruption (Zainal, Md. Som \& Mohamed, 2019). Workplace integrity can take many forms, but it most commonly relates to possessing upstanding character traits and work ethics, such as sound judgement, honesty, dependability, and loyalty. Promoting integrity has become a crucial component of government innovation in most countries. The Malaysian government is continually launching programmes to encourage and motivate integrity practices in all government departments so that their work is more transparent (Alam, Johari \& Said, 2018). Integrity instils principles that support ethical behaviour and encourages people to follow the rules. Thus, having an integrity system is crucial, ensuring accountability and transparency (Alam, Said \& Abd Aziz, 2019).

The government recognises that the public sector has evolved into an essential tool for management, administration, service delivery, and national growth. As a result, all endeavours reflect ethical practices and integrity (Zainal et al., 2019). As a result, Malaysia's Anti-Corruption Agency was established in 1967 with the specific goal of improving the administration's ability to combat corruption and other forms of workplace mismanagement. The administration has made fighting corruption a top priority since 2003, implementing new programmes and techniques. Despite the creation of a framework to combat corruption, there is still work to be done. Malaysian civil workers have an important role in ensuring that government programmes are adequately implemented (Johari, Alam, \& Said, 2020). As a result, top-performing employees are in high demand to help the company achieve its goals and provide the best possible service. Participation in work activities will make public employees feel as if their jobs and their assigned department are more significant. Employees in the public sector who participate in more workflow stages will feel like they have contributed more to meeting the public sector's clients (Johari et al., 2016). Performance is a source of joy, pride, and mastery for public servants.

Employees with high integrity will perform their duties with honesty and a sense of responsibility, just as management expects. They'll surely deliver and set an example for their colleagues. Low performance can lead to emotions of dissatisfaction and, in the worst-case scenario, personal failure. The degree to which the individual perceives the job as generally significant, valuable, and worthwhile. In contrast, the degree to which the individual feels personally accountable and responsible for the work's results is referred to as experienced responsibility for work outcomes. Knowledge of results refers to how well an individual knows and understands how well he or she is consistently executing the work (Johari, Mohd Shamsudin, Tan, Yahya, \& Adnan, 2019).

Job explicit behaviours, which include core job obligations specified as part of the job description, are included in task performance. Task performance necessitates a higher level of cognitive ability, which is primarily facilitated by task knowledge (necessary technical expertise or principles to ensure job performance and the ability to handle multiple assignments), task skill (application of technical expertise to complete tasks successfully without much supervision), and task habits (an innate ability to respond to assigned jobs that require little supervision) (Conway, 1999). As a result, the capacity to do the work and prior experience are the most important antecedents of task performance. Task performance is a contractual agreement between a manager and a subordinate to complete a given task in an organisational context. Technical-administrative task performance and leadership task performance are the two types of entrusted task performance. Technical-administrative task performance refers to the required job performance of planning, organising, and administering day-to-day work using one's technical ability, business judgement, and other skills (Pradhan \& Jena, 2017).

Sonnentag and Frese (2002) documented performance perspectives in three segments. The first is from the standpoint of personal differences. It refers to the persons themselves in cognitive capacity, personality, drive, and professional experience. In this perspective, the fundamental question would be, "Who performs best?" On the other hand, the situational perspective is concerned with variables in a person's surroundings that help or impede performance. The essential question in this perspective would be, "In what circumstances do individuals do particularly well?" Finally, performance regulation refers to the aspects of the action process. The two fundamental questions circling this approach are "What occurs when a person performs?" and "What happens when an individual performs?" "Can you describe the performance procedure?". Subjective, objective, external, and internal factors can all be used to assess performance. It is crucial if a metric provides minimum information while simultaneously achieving other objectives. Both subjective and 
objective metrics are useful for better understanding how organisations work (Van Loon, Vandenabeele \& Leisink, 2017). When objective measurements are used to transmit noisy signals about an individual's actual performance, they can lead to skewed incentives, undue risks for employees, and dysfunctional employee behaviour (Baker, 2000; Feltham \& Xie, 1994; Holmstrom \& Milgrom, 1991; Prendergast, 1999). According to previous research, subjective evaluation can help to alleviate this problem by allowing businesses to use information that cannot be objectively quantified or contracted upon in performance evaluation, thereby reducing incentive distortion and better aligning the interests of the company and its employees (Baiman \& Rajan, 1995; Baker, 2000; Budde, 2007; Rajan \& Reichelstein, 2009). Subjective criteria have the advantage of allowing comparisons across different types of businesses and capturing a more significant amount of employees' multiple aims.

In contrast to objective measures, these metrics are more prone to common method bias and social desirability bias. This study's self-reported performance measure will only give a partial picture of performance. According to Van Loon et al. (2016), employee self-reported general performance is an appropriate measure for a study comparing various diverse businesses since it allows for comparison across firms and jobs instead of more context-specific standards.

\section{Person-Environment Fit}

"We are not all the same; we have distinct natures that are suited to different jobs." This remark first appears in 375 $\mathrm{BC}$ in Plato's dialogue The Republic, authored by the Athenian philosopher Plato. Back then, the person-occupation match was viewed as a critical indicator of city-character states and order. Having the correct person for the work can have many benefits, not just for the individual doing the job, but also for the people and surroundings. After many centuries, Lewin (1997) popularised the field theory, which argued that behaviour (B) is a function (F) of the person (P) and his environment (E). He also argued that to appreciate and explain a person's behaviour completely, one must understand both the individual and his environment, rather than just one of them (Ryu, 2017).

To summarise, this theory comprises three parts: the individual, the behaviour, and the environment. It contends that an individual's behaviour is influenced by both the person and the environment in which they live. Individuals' conduct is influenced by their perceptions of their surroundings (Ashfaq \& Hamid, 2021). Individuals who have a positive impression of the work environment are more likely to behave positively (Udin, 2020). Individuals who identify with the organisation's values are likely to be more engaged at work and in the organisation.

This realisation teaches us that positive individual behaviour is determined by the person and his or her surroundings. Positive individual behaviour, in turn, is essential for positive life outcomes, such as a person's work. PE fit theories are a broad category of congruence-based methods for studying the mutual influences and interactions between personal and work-related factors (Su et al., 2015). Although the level and focus of these theories vary (e.g., basic features, antecedents and consequences, measurement), they all give a framework for researching relationships between people and their workplaces. PE fit is a broad term that refers to a person's compatibility with their work environment, which occurs when their qualities are appropriately matched (Kristof-Brown et al., 2005). PE fit can be divided into two categories. The first, supplementary fit, entails a comparison of the individual with his or her workplace. The second, complementary fit, happens when an individual fills a void or contributes to his or her work environment. There are two types of complementary fit: (1) requirements/supplies, which occurs when the environment fits the individual's wants and preferences, and (2) demand/abilities, which occurs when the individual's skills meet the demands of the work environment (Kristof, 1996).

The fit between a person's knowledge, skills, and attitudes (KSAs) and the demands of a given job (demand-abilities fit) and/or a person's wants and preferences and the job's attributes (needs-supplies fit) is referred to as PJ fit (Kristof, 1996). This dual definition is represented in a fragmented body of research, with a growing number of studies including both criteria (demand-abilities fit and needs-supplies fit) at the same time (Deschenes, 2021). Edwards (1991) suggested the PJ fit, which stated that rewards might be used to meet an employee's requirements or wants. The perception of a difficult job, promotion chances, feeling valued at work, or pleasant working environments (Cable \& DeRue, 2002). PJ fit has been demonstrated to have a positive impact on employee performance and organisational commitment. (KristofBrown et al., 2005). According to a few studies, employees with higher levels of PJ fit also display higher levels of performance and are more driven to gain incentives from the organisation. Employees with a lower degree of PJ fit may have lower performance levels and are less motivated to receive rewards from the company (Cable \& DeRue, 2002).

PO fit refers to the fit between the personal values of employees and the values taught within the organisation. Several types of research have used PO fit as an intervening variable in relationships between PSM and work outcomes (Bright, 2007; Wright \& Pandey, 2008). Public service organisations were surveyed in these studies. They concluded that people with high levels of PSM tend to observe a high level of value congruence with their organisations and consequently demonstrate high levels of performance, job satisfaction, and low levels of quitting intentions. However, a meta-analysis revealed P-O fit as moderately linked with extra-role performance but only weakly linked with job performance (KristofBrown, Zimmerman \& Johnson, 2005). On the contrary, Hoffman and Woehr (2006) found that PO fit was more strongly associated with task performance than organisational citizenship behaviour.

The theory of P-E fit has garnered much interest, especially for exploration in the context of the cultural effect over a decade. Yet, not much empirical research is available on the validity and generalizability of the P-E fit across cultures (Kristof-Brown \& Guay, 2010). PJ and PO fits are seen as most significant in determining behavioural outcomes and are therefore the most studied categories of fit (Kristof-Brown et al., 2005; Lauver \& Kristof-Brown, 2001; Muchinsky \& 
Monahan, 1987). Hence, PJ and PO refer to different environment levels seen as separate constructs (Boon, Hartog, Boselie, \& Paauwe, 2011; Kristof, 1996). Along with the increased importance of P-E fit to organisational operations, non-financial indices of organisational success have gained relevance. Corporate social and ethical performance has grown increasingly relevant due to the number of high-profile ethical issues in recent decades. Indeed, ethical blunders at Volkswagen, Enron, and other corporations have pushed organisational ethics up the priority list of important business practices. Scholars in the domains of industrial organisational psychology, organisational behaviour, and human resource management have conclusively proven that ethical fit is connected with diverse outcomes (e.g., organisational commitment, ethical satisfaction, turnover intentions). The discovery of ethical fit as a robust predictor of individuallevel employee outcomes could have far-reaching ramifications for organisational science and practice. Organisations may establish more robust programmes to promote ethical alignment among individuals, managers, teams, and the entire organisation (George, Jr., 2021).

Several studies have researched the relationship between PJ fit and performance (Ambrose, Arnaud \& Schminke, 2008; Kristof-Brown, Zimmerman \& Johnson, 2005; Cable \& DeRue, 2002) as well as PO fit and performance (KristofBrown, Zimmerman \& Johnson, 2005; Hoffman \& Woehr, 2006). Stejin (2008), in his study on PE fit and PSM, measured only one type of fit (PJ fit). However, he suggested that other types of fit (e.g., PO fit) can be essential for public sector employees. In reality, it is likely for someone who values PSM to remain unaffected by a PJ misfit, provided they experience PO fit at the same time. He also concluded that such a situation could happen if the organisation contributes to the betterment of the public even if the person's job does not directly do so. Another factor to note is that a firm strives to recruit persons viewed as possessing values comparable to those espoused by the firm. Later, through official and informal socialisation processes, the firm strengthens the value congruence factor such as integrity that has been accomplished during the initial selection and recruitment process.

Furthermore, according to the interest alignment theory, a firm strives to propagate existing norms and values among employees by developing organisation identification (Uppal, 2021). Therefore, evaluation of the fit should include both PJ and PO fits to get a better understanding. Based on the prior studies, this paper hypothesises the following:

H1: Person-job fit has a positive and significant effect on the integrity and individual performance

H2: Person-organisation fit has a positive and significant effect on the integrity and individual performance

\section{Public service motivation}

Various dimensions of motivation have been researched worldwide, and several theories have been developed in connection to it. In general, motivation is defined as the forces that energise, direct and sustain behaviour (Perry \& Porter, 1982). Public Service Motivation is a widely used theory in studies related to public service. The measurement scale for Public Service Motivation was formally introduced in 1990 (Perry \& Wise, 1990). Several definitions were coined as the theory evolved over the years. However, for this research, one of the more recent definitions is used. The PSM in this study is defined as the beliefs, values, and attitudes that go beyond self-interest and organisational interest, which concern the interest of a larger political entity, motivating individuals to act accordingly whenever appropriate (Vandenabeele, 2007). As such, PSM can serve as a personal resource for employees to expand their repertoire of structural and social resources to serve the public good (Luu, 2020).

PSM is seen to be a good predictor of public-sector performance. Many academics believe that when PSM rises, public employees' performance will increase as well. However, the findings of two published studies investigating this concept are contradictory (Bright, 2007). According to certain studies, PSM can also act as a moderator that interacts with other variables (Potipiroon \& Faerman, 2016). For example, those between red tape and negative employee attitudes (Quratulain \& Khan, 2013); citizen participation - perceived importance and evaluation (Coursey, Yang \& Pandey, 2012); work-related stressors and employee health outcomes (Liu, Yang \& Yu, 2014); mistreatment at work and counterproductive work behaviour and mistreatment at work and counter-productive work behaviour (Potipiroon \& Ford, 2017) are among the studies that showed the moderating function (Bottomley, Mostafa, Gould-Williams \& Leon-Cazares, 2015). Kim and Vandenabeele (2010) documented that countries vary in national values and their organisational culture. These differences influence differences in PSM observed in different countries. In a two-decade analysis article, researchers also stated that linguistic, context, and culture should be considered in PSM research as the internationalisation of research proceeds. They also noted that it would be interesting to study how PSM and performance interact over time, where causal relationships between PSM and performance will be incredibly informative for both theory and practice. (Perry, Hondeghem \& Wise, 2010).

Furthermore, those who dedicate themselves to the greater good of society may better deal with hindrance job demands because they understand that dealing with hindrance job demands (such as those from demanding citizen-clients) supports the bigger goal of supporting citizens (Bakker, 2015).In this study, the relationship between the PJ fit and PO fit with individual performance is hypothesised to be positive. Additionally, testing whether PSM can improve the strength of this relationship can be helpful for public sector managers in crafting strategies to enhance the performance of their employees if the study proves this hypothesis to be significant. This conceptual model will allow us to observe the impact of PSM on public sector employees with PJ fit and PO fit as predictors of performance. Based on this gap, this paper also hypothesises the following: 
H3: Public service motivation positively moderates the relationship between person-job fit and integrity and individual performance

H4: Public service motivation positively moderates the relationship between person-organisation fit and the integrity and individual performance

\section{Conceptual framework}

The conceptual framework of this study is shown in Figure 1. First, it was developed to investigate the effect of P-J and P-O fit on individual performance. Next, the moderating effect of PSM on this relationship is tested. Finally, this conceptual framework is tested on the state-level public sector employees in Penang.

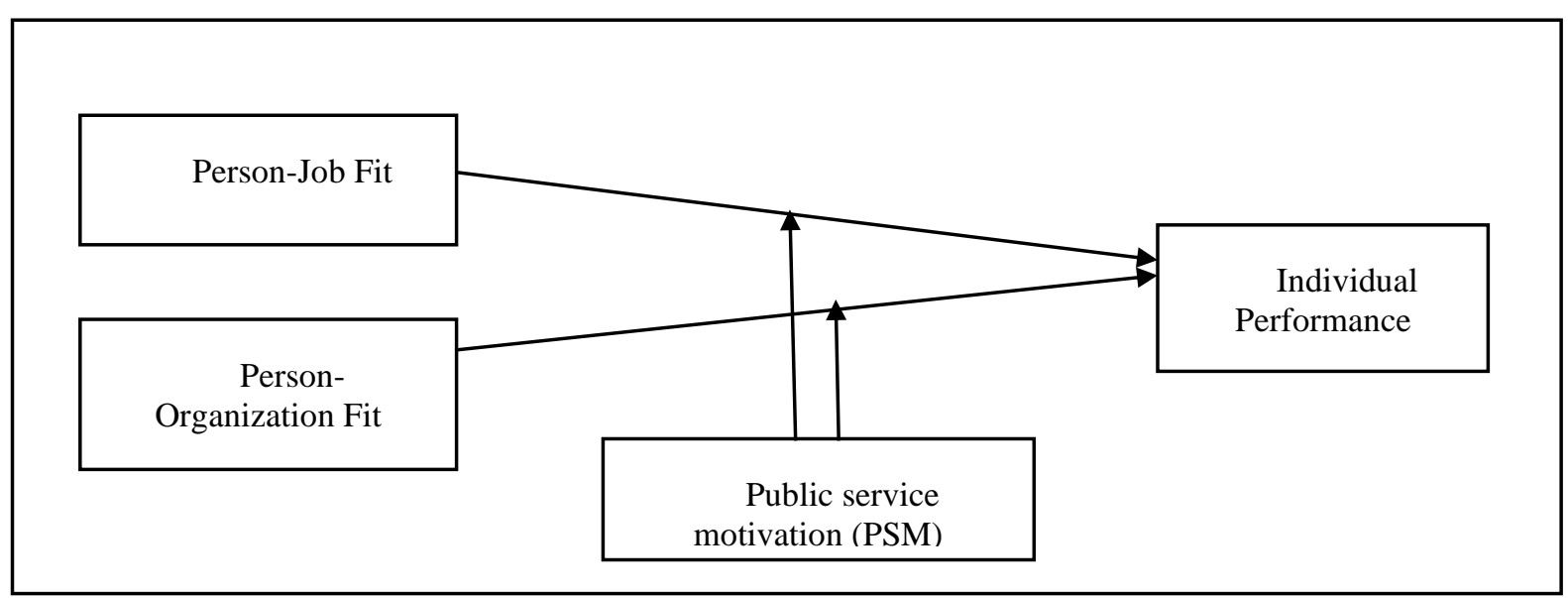

Figure 1. Conceptual Framework

\section{METHOD}

\section{Sample}

In this study, the quantitative method was applied. This study's participants are state-level public sector personnel in Penang, who work for 14 state departments, 5 land and district offices, 2 city councils, and 5 state agencies. Because of its proximity and accessibility, Penang was chosen for sampling. In this study, the convenience sampling method was used. The survey was conducted online and sent to the target audience in two ways: via WhatsApp and formal emails. The survey was completely anonymous, and participation was completely voluntary. There were a total of 214 responses. As determined by the $\mathrm{G}^{*}$ Power analysis, the smallest sample size required to detect the test's effect, as determined by the $\mathrm{G}^{*}$ Power analysis, was 74 . Table 1 summarises the demographics of the respondents. The majority of the respondents $(57.9 \%)$ are women between the ages of 25 and 44. (85.1 per cent). With 6 to 20 years of service tenure, most of them have obtained higher education $(85.6 \%)$ and are currently employed in managerial and professional positions and support roles in the service plan (98.6\%). (81.3 per cent). The state secretariat, state departments, and the district and land office received the most responses (72.5 per cent).

Table 1. Respondents Profile

\begin{tabular}{|l|l|c|c|}
\hline \multicolumn{2}{|c|}{ Demographic Variables } & Frequency & Percentage \\
\hline Gender & Male & 90 & 42.1 \\
& Female & 124 & 57.9 \\
\hline \multirow{2}{*}{ Age } & $25-34$ years old & 65 & 30.4 \\
& $35-44$ years old & 117 & 54.7 \\
& $45-54$ years old & 28 & 13.1 \\
& 55 years old and above & 4 & 1.9 \\
\hline Education & SPM & 31 & 14.5 \\
& Diploma/STPM & 53 & 24.8 \\
& Degree & 95 & 44.4 \\
& Master & 33 & 15.4 \\
& PhD & 1 & 0.5 \\
& Others & 1 & 0.5 \\
\hline Service Scheme & Top Management & 3 & 1.4 \\
& Management \& Professional & 104 & 48.6 \\
& Support & 107 & 50.0 \\
\hline
\end{tabular}




\begin{tabular}{|l|l|c|c|}
\hline Organization & State Secretariat & 59 & 27.6 \\
& State Department & 55 & 25.7 \\
& District \& Land Office & 41 & 19.2 \\
& City Council & 38 & 17.7 \\
& State Agency & 21 & 9.8 \\
\hline Service Tenure & $1-5$ years & 27 & 26.6 \\
& 6-10 years & 57 & 39.3 \\
& $11-15$ years & 84 & 15.4 \\
& $16-20$ years & 33 & 4.2 \\
& 21-25 years & 9 & 1.9 \\
\hline
\end{tabular}

\section{Measurement instrument}

This study collected its data through a questionnaire comprising 5 sections: PJ fit items, PO fit items, PSM items, individual performance items, and respondents' personal information. Questionnaire items used in past studies were adapted in the present research to maintain content validity. The PJ fit, PO fit and PSM items were adapted from Van Loon, Vandenabeele \& Leisink (2017). A five-point Likert scale was used to examine all the items, and the respondents were required to respond to each item by selecting options ranging from 1 (Strongly Disagree) to 5 (Strongly Agree). The item for individual performance was adapted from Singh, Verbeke \& Rhoads (1996) with a five-point Likert scale, where respondents are required to respond to each item by selecting options ranging from 1 (Poor) to 5 (Excellent). The personal information section consisted of 6 questions on gender, age, education level, current service scheme, the organisation they work in, and service length.

\section{RESULTS}

Data collected were analysed using the IBM SPSS and SmartPLS version 3.0. The descriptive analysis and identification of missing values were made in SPSS. The hypotheses were tested using the Partial Least Square approach via the Smart PLS Version 3.0. Firstly, the validity and reliability of the measures are evaluated based on formative and reflective specifications. Next, the structural model estimates are assessed once the above measurements are considered significantly sufficient to perform such an assessment.

\section{Measurement model results}

The validity and reliability of the measurement model were established in the first step. Items with factor loadings of 0.6 are acceptable (Hair et al., 2011). Next, the internal consistency reliability is measured using composite reliability (CR). Table 2 shows that the CR of all constructs was above 0.7 , which satisfies the rule of thumb in Hair et al. (2014). Finally, the average variance extracted (AVE) was used to assess convergent validity. The AVE of all constructs was more than 0.5 , which indicates a satisfactory degree of convergent validity (Fornell \& Larcker, 1981).

Next, the discriminant validity was calculated. Henseler, Ringle and Sarstedt (2015) recommended the heterotrait-monotrait (HTMT) ratio of the correlations (Voorhees, Brady, Calantone, \& Ramirez, 2016). A 0.9 threshold value is recommended for constructs with similar concepts, while a lower threshold value of 0.85 is recommended for more distinct constructs. (Henseler et al., 2015). Table 3 shows the HTMT value is lower than the 0.85 threshold value for all constructs measured.

From the PE fit theory, PJ fit and PO fit are reflections of PE fit, thus proposing a second-order construct. Similar measurement model valuation measures were applied among second-order constructs and their first-order constructs and between all the first-order constructs in second-order constructs (Hair et al., 2014). The analysis shows satisfactory individual item reliability, as each scale had loadings greater than 0.6 (Table 4). The CR (0.926) and the AVE (0.613) also met the reliability and convergent validity criteria. 


\begin{tabular}{|c|c|c|c|c|}
\hline Constructs & Items & $\begin{array}{l}\text { Factor } \\
\text { Loadings }\end{array}$ & CR & AVE \\
\hline PJ Fit & $\begin{array}{l}\text { 1. The attributes that I look for in a job are fulfilled very well } \\
\text { by my job. } \\
\text { 2. My job does not enable me to do the work I would like to do. } \\
\text { 3. My job allows me to work on goals that I personally see as } \\
\text { important. } \\
\text { 4. If I think about what I would like to achieve, I sometimes } \\
\text { doubt whether I chose the right job. } \\
\text { 5. There is a good match between my personal interests, values, } \\
\text { and the kind of work that I do. }\end{array}$ & $\begin{array}{l}0.764 \\
0.748\end{array}$ & 0.892 & 0.624 \\
\hline PO Fit & $\begin{array}{l}\text { 1. There is a match between what I think is important in my } \\
\text { work and what my organisation thinks is important. } \\
\text { 2. My values match or fit the values of this organisation. } \\
\text { 3. What this organisation stands for is very important to me. }\end{array}$ & $\begin{array}{l}0.941 \\
0.859\end{array}$ & 0.937 & 0.833 \\
\hline $\begin{array}{l}\quad \text { Public } \\
\text { Service } \\
\text { Motivation } \\
\text { (PSM) }\end{array}$ & $\begin{array}{l}\text { 1. I think it is important to be part of activities aimed at solving } \\
\text { social problems. } \\
\text { 2. It is important for me to contribute to the common good. } \\
\text { 3. I think equal opportunities for citizens are very important. } \\
\text { 4. It is important that citizens can rely on the provision of } \\
\text { accessible public services. } \\
\text { 5. Considering the welfare of others is very important to me. } \\
\text { 6. I empathize with other people who face difficulties. } \\
\text { 7. I would agree to a good plan to make life better for the poor, } \\
\text { even if it costs me money. }\end{array}$ & $\begin{array}{l}0.712 \\
0.737 \\
0.682 \\
0.688 \\
0.797 \\
0.765 \\
0.689\end{array}$ & 0.886 & 0.526 \\
\hline $\begin{array}{l}\text { Individual } \\
\text { Performance } \\
\text { (IP) } \\
\quad \text { Please } \\
\text { rate yourself } \\
\text { in terms of... }\end{array}$ & $\begin{array}{l}\text { 1. Quantity of work you achieve. } \\
\text { 2. Your ability to reach your job goals. } \\
\text { 3. Your performance potential among co-workers in your } \\
\text { organization. } \\
\text { 4. Management of time, planning ability and management of } \\
\text { expenses at work? } \\
\text { 5. Knowledge of your job, integrity, organization and customer } \\
\text { needs? }\end{array}$ & $\begin{array}{l}0.876 \\
0.869 \\
0.868\end{array}$ & 0.947 & 0.780 \\
\hline
\end{tabular}

$\mathrm{CR}=$ Composite Reliability; AVE $=$ Average Variance Extracted 


\begin{tabular}{|c|c|c|c|}
\hline Construct & IP & P-J FIT & P-O FIT \\
\hline IP & & & \\
P-J FIT & 0.491 & & \\
P-O FIT & 0.523 & 0.831 & 0.507 \\
PSM & 0.41 & 0.415 & \\
\hline
\end{tabular}

Table 4. Assessing the Second-Order Constructs (factor loadings)

\begin{tabular}{|c|c|c|c|c|}
\hline Construct & Item & Factor Loadings & CR & AVE \\
\hline PE Fit & PJ Fit & 0.896 & 0.926 & 0.613 \\
& PO Fit & 0.836 & & \\
\hline
\end{tabular}

\section{Structural model}

Path coefficients may show a bias if the approximation involves substantial levels of collinearity between predictor constructs, similar to regular multiple regression. (Hair et al., 2014). To address this concern, the variance inflation factor (VIF) was used to investigate multicollinearity. A VIF value greater than 5 indicates multicollinearity (Hair et al., 2011). As can be seen in Table 5, all VIF values are less than 5. In the structural model, collinearity between predictor constructs is not a concern, and therefore, the analysis can be continued.

Table 5. Multicollinearity Assessment

\begin{tabular}{|c|c|}
\hline Constructs & VIF \\
\hline PJ Fit & 2.280 \\
PO Fit & 2.485 \\
\hline
\end{tabular}

The accuracy of the model's predictions was determined using the proportion of variance explained (Kurniawan, Zailani \& Iranmanesh, 2017). The coefficient of determination $\left(\mathrm{R}^{2}\right.$ value $)$ specifies the degree to which predictor constructs can explain or predict the dependent construct. The $\mathrm{R}^{2}$ value for individual performance is 0.320 , which is well above the 0.26 suggested by Cohen (1988). The $\mathrm{Q}^{2}$ value greater than zero implies that the model has predictive relevance (Chin, 2010). The $\mathrm{Q}^{2}$ values for individual performance are 0.231 , which means that the model has predictive relevance.

The non-parametric bootstrapping was used to examine the structural model with 2000 replications (Wetzels et al., 2009). The results in Table 6 indicate that the effects of both PJ fit $(\beta=0.165, p<0.05)$ and PO Fit $(\beta=0.244, p<0.01)$ on individual performance are significant and positive. Therefore, $\mathrm{H} 1$ and $\mathrm{H} 2$ are supported. After examining the direct effects within the model, the next step is to test the moderating effect of Public Service Motivation. The interaction effect (product term) is used to test the moderating effect. The results indicate that Public Service Motivation does not moderate the relationship between PJ fit $(\beta=0.010, p=0.473)$ and PO fit $(\beta=0.169, p=0.119)$ and individual performance. Therefore, both $\mathrm{H} 3$ and $\mathrm{H} 4$ are not supported.

Table 6. Path coefficient and hypotheses testing

\begin{tabular}{|c|c|c|c|c|c|}
\hline \multirow[b]{2}{*}{ Hypothesis } & \multirow[b]{2}{*}{ Relationships } & \multirow{2}{*}{$\begin{array}{c}\text { Path } \\
\text { Coefficients }\end{array}$} & \multirow[b]{2}{*}{ t-value } & \multicolumn{2}{|c|}{ Confidence Interval } \\
\hline & & & & $\mathbf{L L}$ & $\mathbf{U L}$ \\
\hline \multicolumn{6}{|l|}{ Main model } \\
\hline H1 & PJ Fit -> IP & 0.165 & $1.799 *$ & -0.004 & 0.366 \\
\hline H2 & PO Fit -> IP & 0.244 & $2.357 * *$ & 0.029 & 0.429 \\
\hline \multicolumn{6}{|c|}{ Moderating effect } \\
\hline H3 & PJ Fit*PSM -> IRP & 0.010 & 0.068 & -0.261 & 0.304 \\
\hline H4 & PO Fit*PSM -> IRP & 0.169 & 1.178 & -0.251 & 0.320 \\
\hline
\end{tabular}




\section{DISCUSSION AND IMPLICATIONS}

Empirical results show that PJ fit positively impacts integrity and individual performance. The result is consistent with Kristof-Brown, Zimmerman, and Johnson (2005) findings where PJ fit was positively associated with staff performance and organisational commitment. Cable \& DeRue (2002) also concluded that employees with greater levels of PJ fit might also exhibit more significant levels of performance than those having lower levels of PJ fit. From the perspective of Malaysian public servants, the work done is consistent with their internal value of integrity. Since the Malaysian government places a strong emphasis on ethical ideals, including integrity and other desirable qualities, it is clear that public servants have incorporated integrity into their daily work lives. They executed their job with dignity and honoured the oath they have sworn on during their onboarding in their respective department.

The outcome of the analysis also shows that PO fit positively impacts integrity and individual performance. Organisational culture is crucial for individual performance. This finding corroborates Hoffman and Woehr (2006) findings that concluded that PO fit was more strongly associated with task performance than organisational citizenship behaviour. This study shows that PO fit can also be an important measure for behavioural outcomes and not only organisational outcomes. Additionally, Bright (2007) indicated that individuals would perform their best in public sector organisations that fulfil their vital needs and support their skills and abilities.

Consequently, the PO fit literature proposes that individuals who achieved compatibility with their organisation will perform better than those who are less compatible. This also demonstrates that an organisation that emphasises integrity and other ethical behaviours encourages public servants to perform their best work. Excellence and integrity are inextricably linked. Excellence will be attained by a public servant who fulfils his responsibilities with honesty. When a public servant is fully engaged in his or her duties, he or she will generate high-quality work that can be completed swiftly and effectively. Also, the customer's services are well-executed and courteous. Doing the right thing is what integrity is all about. When no one is looking, do the right thing. It's a choice between what's practical and what's ethical.

When studying both types of fit concurrently, we could see that the positive effect of PO fit is relatively more substantial than the effect of PJ fit on individual performance. These findings are consistent with Stejin's (2008) conclusion that the fit should include PJ and PO fits to understand better. However, a person with a PJ misfit can still perform well given that the organisation contributes to the betterment of the public even if the person's job does not directly do so. As a result, public servants must demonstrate integrity in their work by using trust and power for the greater benefit. If non-integrity behaviour becomes widespread, it will destroy society's confidence, damaging workers' reputations, the country's economy, and weakening big commercial institutions. Therefore, integrity among public servants is undoubtedly important to cultivate to build a competitive and flourishing Malaysia.

The interaction graph is illustrated in Figures 2 and 3 below. The unsupported hypotheses do not mean that there were no interactions, but the positive relationship may be statistically insignificant. Additionally, Figure 3 shows a high likelihood that interaction had occurred outside the observed range of value. It is known as the ordinal interaction. It suggests that the moderating effect of PSM on the relationship between PO fit and individual performance was nearly significant for the sample collected. A range restriction issue may have made the moderation effect at the population level seem smaller than the actual or even made it statistically not significant (Aguinis, Edwards, \& Bradley 2017).

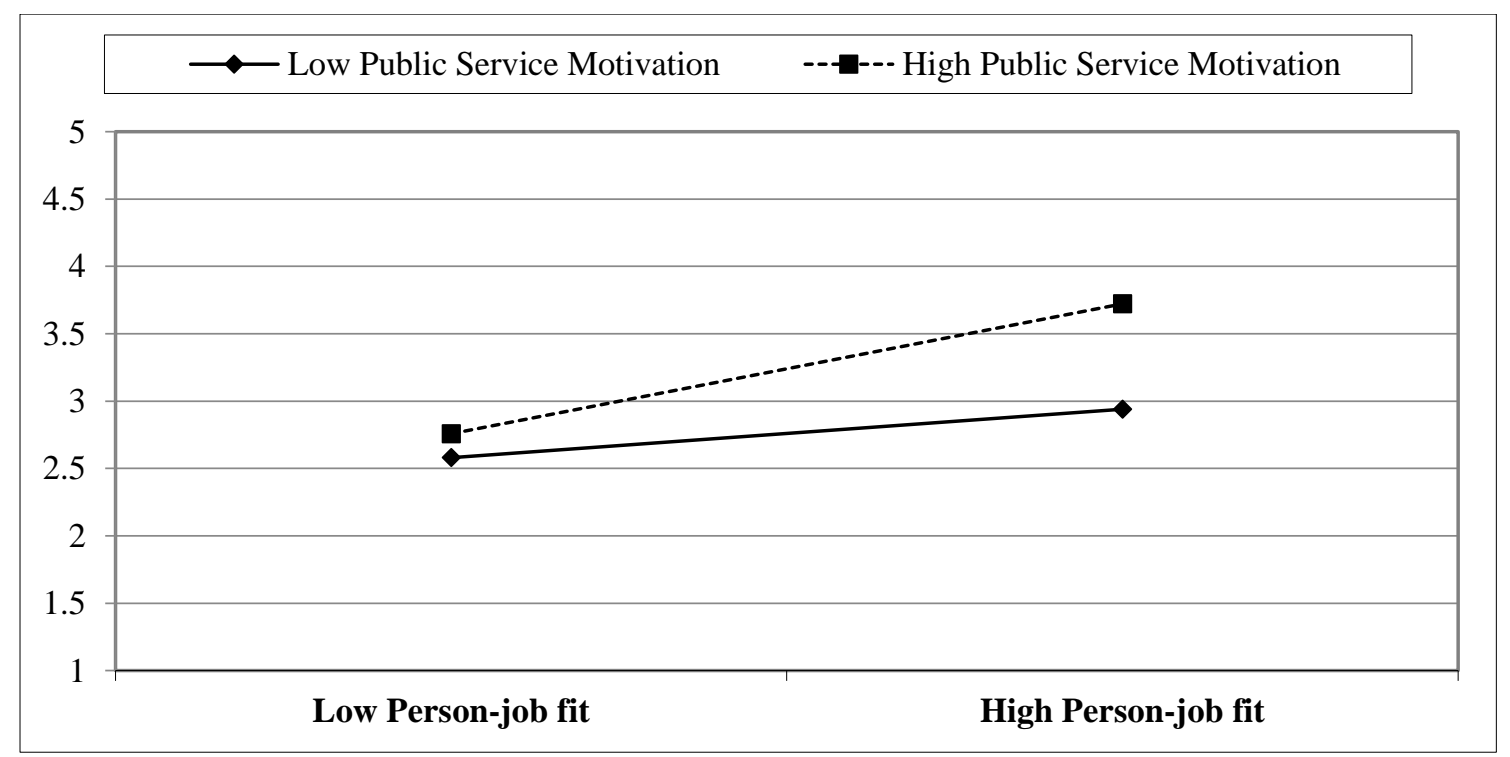

Figure 2. Interaction Effect of PSM in the relationship between PJ fit and individual performance 


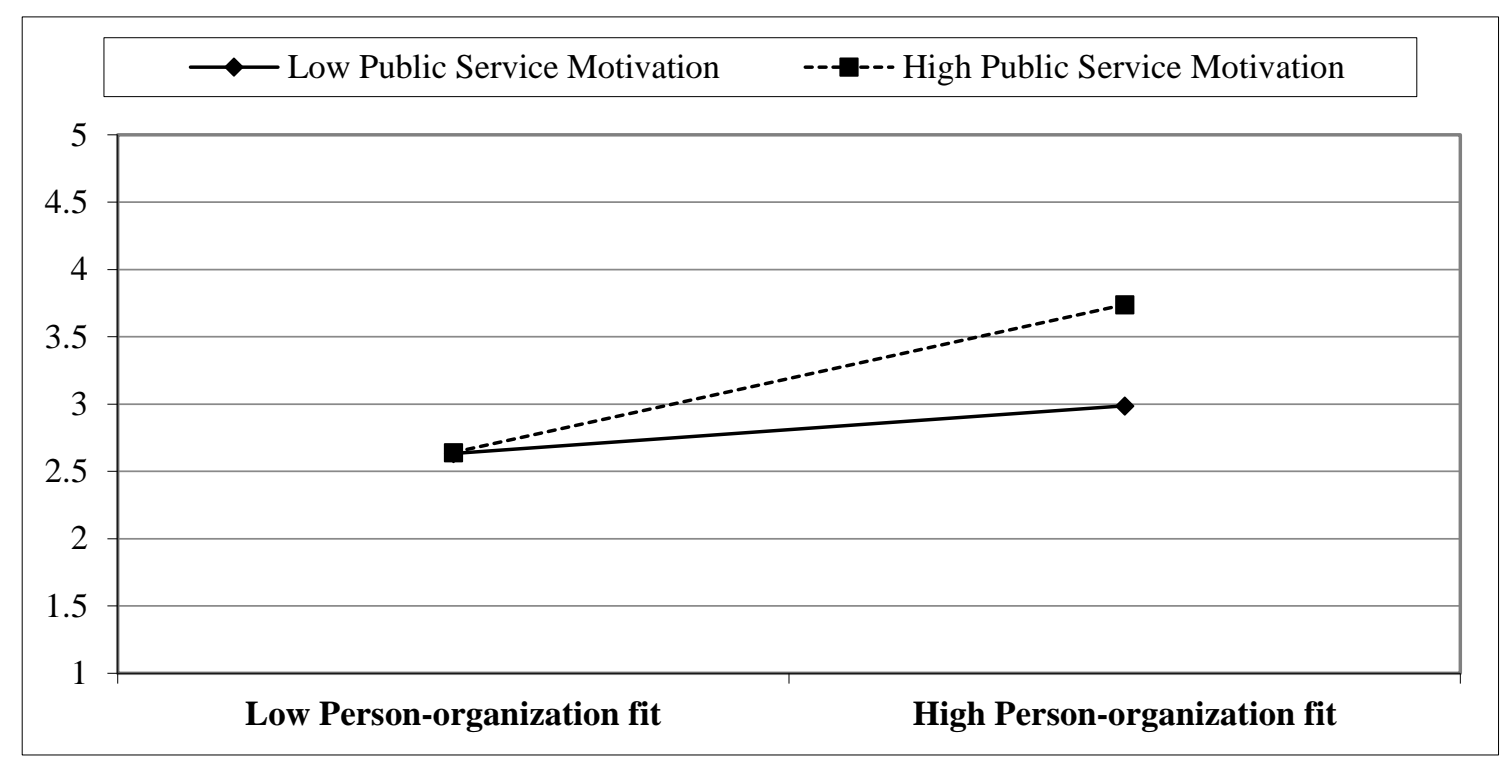

Figure 3. Interaction Effect of PSM in the relationship between PO fit and individual performance

Concerning the statistically insignificant interaction of PSM in this study, two aspects highlighted by Perry, Hondeghem \& Wise (2010) are relevant. First, the conceptualisation of PSM itself. The PSM research was primarily focused in the United States and has now diffused to Europe, Australia, South America, and Asia. As a result, the values linked with public service across countries are different, where the meanings of PSM may also differ and are less established in some countries. Second, language is an important aspect of international research. The present study used a bilingual questionnaire (English and Bahasa Malaysia) to address the respondents better. Although careful considerations were given during the translation, similar wordings may bring different cultural meanings and distort findings. The outcome of this study, particularly on the PSM variable, supports the call by Perry, Hondeghem \& Wise (2010) to consider revising operationalisation and constructs of PSM.

The $\mathrm{R}^{2}$ value for this study suggests $32 \%$ of the variance in individual performance can be explained by the personjob fit and person-organisation fit. These findings tell us that other factors affect the performance of public sector employees, which is not captured in this study. Thus, other possible variables that can be considered include ethical climates, workplace religiosity and personality traits. As for the self-reported performance data, past literature discussed the methods for collecting performance data, including collection via physical records of the respondent from their respective supervisors or work organisations. However, this will uncover the identities of the respondents. There is a strong possibility that many respondents would not have participated in the survey without anonymity, given the nature of the survey questions. To overcome the bias, the questionnaire design includes using clear and straightforward language and explaining the importance of responses for the questions, how they will be used, and the requirement of accurate responses (Jakobsen \& Jensen, 2015).

Conway and Lance (2010) highlighted that other methods such as objective measures are often superior to self-reports. It may be because the self-reports method effects decrease construct validity. Self-reports can be subjected to method effects, but the biasing factors such as social desirability do not have consistent, strong effects. More importantly, other methods such as supervisor ratings and peer ratings are also subjected to method effects (response biases).

Academically, the outcome of this study adds to the literature of studying both PJ fit, and PO fit concurrently and its effect on integrity and individual performance, particularly in the context of the public sector. This study also provides input to the existing literature on the consistency of PSM across different cultures. Practically, when both the fit are studied concurrently, we can see that PO fit bears a greater significance on the integrity and individual performance of public sector employees in Penang. It provides excellent insight for public sector managers and leaders. While PJ fit may be challenging to achieve in a public organisation setting, PO fit can be emphasised to achieve greater integrity and individual performance amongst public sector employees. In other words, integrity and performance outcomes are magnified when individual characteristics match the organisation's culture. It will be helpful, especially in recent times where the stakeholders' expectations are momentously rising. Last but not least, the outcome of this study will also help allocate government resources to the right initiatives in boosting the integrity and performance levels of public sector employees, who are the heart of the public service.

\section{LIMITATIONS AND FUTURE RESEARCH}

This study has several limitations that should be considered before the generalisation of the results. First, the sample of this study consisted of state-level public sector employees in Penang. While public service in Malaysia generally focuses on providing service to the citizen, the study's outcome may vary, especially for samples of public sector employees in specialised service sectors such as safety or education. Second, the study is exploratory and tested the 
hypotheses via a questionnaire survey. This method limits the ability to indicate causality in the relationships between variables tested. For more accuracy, longitudinal research to study the relationships over an extended period is recommended.

\section{CONCLUSION}

The study aimed to test the effects of PJ fit and PO fit on integrity and individual performance and investigate the moderation effect of PSM on the integrity and individual performance of public service employees. To test the conceptual framework developed, 214 data were collected via an online questionnaire from public sector employees in Penang statelevel public organisation. The results indicate that both PJ fit and PO fit positively affect the integrity and individual performance. Relatively, the PO fit is having a more substantial positive impact on the integrity and individual performance. The interaction between PJ fit and PSM on integrity and individual performance is statistically not significant. However, the interactions of PSM with PO fit have a near significant effect on the integrity and individual performance where ordinal interaction is suggested to have taken place. The findings show that public sector organisations should strengthen organisational cultures to ensure that PO fit is attained while also inculcating PSM among the employees to achieve better PO fit. The findings allow us to conclude that the top management in the public sector should promote higher levels of PO fit. It can be done by emphasising its values, integrity, and goals while maintaining a consistent and robust organisational culture. However, the PO fit must be optimally achieved and highly encouraged. A low PO fit may cause heterogeneity, which can cause employees difficulty in communication and unsupportive common organisational goals. In contrast, a high PO fit may cause homogeneity, which can cause an inability to change.

\section{ACKNOWLEDGEMENT}

The authors would like to thank the Penang State Government staff for their assistance.

\section{REFERENCES}

Aguinis, H., Edwards, J. R., \& Bradley, K. J. (2017). Improving our understanding of moderation and mediation in strategic management research. Organizational Research Methods, 20(4), 665-685.

Alam, M. M., Johari, R. J., \& Said, J. (2018). An empirical assessment of employee integrity in the public sector of Malaysia. International Journal of Ethics and Systems, 34(4), 458-471.

Alam, M. M., Said, J., \& Abd Aziz, M. A. (2019). Role of integrity system, internal control system and leadership practices on the accountability practices in the public sectors of Malaysia. Social Responsibility Journal, 15(7), 995-976.

Ambrose, M. L., Arnaud, A., \& Schminke, M. (2008). Individual Moral Development and Ethical Climate: The Influence of PersonOrganization Fit on Job Attitudes. Journal of Business Ethics, 77(3), 323-333.

Ashfaq, B., \& Hamid, A. (2021). Person-organisation fit and organisation citizenship behavior: modeling the work engagement as a mediator. Asia-Pacific Journal of Business Administration, 13(1), 19-39

Baiman, S., \& Rajan, M. V. (1995). The informational advantages of discretionary bonus schemes. The Accounting Review, 70(4), $557-579$

Baker, G. (2000). The use of performance measures in incentive contracts. American Economic Review, 90(2), 415-420.

Bakker, A.B. (2015). A Job Demands-Resources approach to public service motivation. Public Administration Review, 75(5), 723732

Bellé, N. (2012). Experimental Evidence on the Relationship between Public Service Motivation and Job Performance. Public Administration Review, 73(1), 143-153.

Bernama, (2020). Corruption: 'Silent Killer' of Civil Servants' Credibility. The Sundaily. December 9. Available online: https://www.astroawani.com/berita-malaysia/corruption-silent-killer-civil-servants-credibility-272316 (accessed on 21 June 2021).

Boon, C., Den Hartog, D. N., Boselie, P., \& Paauwe, J. (2011). The relationship between perceptions of HR practices and employee outcomes: examining the role of person-organisation and person-job fit. The International Journal of Human Resource Management, 22(1), 138-162.

Bottomley, P., Mostafa, A. M. S., Gould-Williams, J. S., \& León-Cázares, F. (2016). The impact of transformational leadership on organizational citizenship behaviours: The contingent role of public service motivation. British Journal of management, 27(2), 390-405.

Bright, L. (2007). Does Person-Organization Fit Mediate the Relationship Between Public Service Motivation and the Job Performance of Public Employees? Review of Public Personnel Administration, 27(4), 361-379.

Budde, J. (2007). Performance measure congruity and the balanced scorecard. Journal of Accounting Research, 45(3), 515-539

Cable, D. M. (1996). Person-Organization Fit, Job Choice Decisions, and Organizational Entry. Organisational Behavior and Human Decision Processes, 67(3), 294-311.

Cable, D. M., \& DeRue, D. S. (2002). The Convergent and Discriminant Validity of Subjective Fit Perceptions. Journal of Applied Psychology 87(5), 875-884.

Cable, D.M., \& Judge, T.A. (1996). Person-organization fit, job choice decisions, and organizational entry. Organizational Behavior and Human Decision Processes, 67(3), 294-311

Christensen, R. K., \& Wright, B. E. (2011). The Effects of Public Service Motivation on Job Choice Decisions: Disentangling the Contributions of Person-Organization Fit and Person-Job Fit. Journal of Public Administration Research and Theory, 21(4), 724743. 
Cohen, J. (1988). Statistical power analysis for the behavioral sciences (2nd ed.). Hillsdale, NJ: Erlbaum.

Conway, J.M. (1999). Distinguishing contextual performance from task performance for managerial jobs. Journal of Applied Psychology, 84(3), 3-13.

Coursey, D., Yang, K., \& Pandey, S. K. (2012). Public service motivation (PSM) and support for citizen participation: A test of Perry and Vandenabeele's reformulation of PSM theory. Public Administration Review, 72(4), 572-582.

Deschênes, A. A. (2021). Satisfaction with work and person-environment fit: are there intergenerational differences? An examination through person-job, person-group and person-supervisor fit. International Journal of Organization Theory \& Behavior. 24(1), $60-75$.

Edwards, J. R. (1991). Person-job fit: A conceptual integration, literature review, and methodological critique. In Cooper CLRIT (Ed.), International review of industrial and organisational psychology, Vol. 6, 283-357.

Feltham, G. A., \& Xie, J. (1994). Performance measure congruity and diversity in multitask principal/agent relations. The Accounting Review, 69(3), 429-453

Fornell, C., \& Larcker, D. F. (1981). Evaluating structural equation models with unobservable variables and measurement error. Journal of marketing research, 18(1), 39-50.

George Jr, F. (2021). Ethical person-environment fit: An integrative definition, key findings, and a call for future research. Human Resource Management Review, Article in Press. https://doi.org/10.1016/j.hrmr.2021.100840

Grindle, M. S., \& Hilderbrand, M. E. (1995). Building sustainable capacity in the public sector: What can be done? Public Administration and Development, 15(5), 441-463.

Gul, H., Usman, M., Liu, Y., Rehman, Z., \& Jebran, K. (2018). Does the effect of power distance moderate the relation between personenvironment fit and job satisfaction leading to job performance? Evidence from Afghanistan and Pakistan. Future Business Journal, Vol. 4, 68-83.

Hair, J. F., Sarstedt, M., Hopkins, L., \& Kuppelwieser, V. G. (2014). Partial least squares structural equation modeling (PLS-SEM): An emerging tool in business research. European Business Review. 26(2), 106-121.

Hair, J. F., Ringle, C. M., \& Sarstedt, M. (2011). PLS-SEM: Indeed, a silver bullet. The Journal of Marketing Theory and Practice, 19(2), 139-152.

Haron, H., Jamil, N. N., \& Ramli, N. M. (2020). Western and Islamic Values and Ethics: Are They Different?, Journal of Governance and Integrity, 4(1), 12-28.

Hashim, N. (2017). Development efforts and public sector corruption in Malaysia: issues and challenges, Journal of Sustainability Science and Management, 12(2), 253-261

Henseler, J., Ringle, C. M., \& Sarstedt, M. (2015). A new criterion for assessing discriminant validity in variance-based structural equation modeling. Journal of the academy of marketing science, 43(1), 115-135.

Hoffman, B.J., \& J.Woehr, D. (2006). A quantitative review of the relationship between person-organisation fit and behavioral outcomes. Journal of Vocational Behavior, 68(2006), 389-399.

Holmstrom, B., \& Milgrom, P. (1991). Multitask principal-agent analyses: Incentive contracts, asset ownership, and job design. Journal of Law, Economics and Organisations, Vol. 7, 24-52.

Jakobsen, M., \& Jensen, R. (2015). Common method bias in public management studies. International Public Management Journal, 18(1), 3-30.

Johari, R. J., Alam, M. M., \& Said, J. (2020). Empirical assessment on factors contributing to integrity practices of Malaysian public sector officers. Business Process Management Journal. Vol. ahead-of-print No. ahead-of-print1463-7154

Johari, J., Shamsudin, F. M., Yean, T. F., Yahya, K. K., \& Adnan, Z. (2019). Job characteristics, employee well-being, and job performance of public sector employees in Malaysia. International Journal of Public Sector Management. 32(1), 102-119

Johari, J., \& Yahya, K. K. (2016). Job characteristics, work involvement, and job performance of public servants. European Journal of Training and Development, 40(7), 554-575

Kim, S., \& Vandenabeele, W. (2010). A Strategy for Building Public Service Motivation Research Internationally. Public Administration Review, 70(5), 701-709.

Kristof, A. L. (1996). Person-Organization Fit - An Integrative View of Conceptualization, Measurements and Implications. Personnel Psychology, 49(1), 1-49.

Kristof-Brown, A. L., Zimmerman, R. D., \& Johnson, E. C. (2005). Consequences Of Individuals' Fit At Work: A Meta-Analysis Of Person-Job, Person-Organization, Person-Group, And Person-Supervisor Fit. Personnel Psychology, 58, 281-342.

Kristof-Brown, A., \& Guay, R. P. (2011). Person-environment fit. In S. Zedeck (Ed.), APA handbook of industrial and organizational psychology, Vol. 3: Maintaining, expanding, and contracting the organization. APA handbooks in psychology (pp. 3-50). American Psychological Association: Washington, DC

Kurniawan, R., Zailani, S. H., Iranmanesh, M., \& Rajagopal, P. (2017). The effects of vulnerability mitigation strategies on supply chain effectiveness: risk culture as moderator. Supply Chain Management: An International Journal, 22(1), 1-15

Lauver, K. J., \& Kristof-Brown, A. (2001). Distinguishing between Employees' Perceptions of Person-Job and Person-Organisation Fit. Journal of Vocational Behavior, 59, 454-470.

Leisink, P., \& Steijn, B. (2009). Public service motivation and job performance of public sector employees in the The Netherlands. International Review of Administrative Sciences, 75(1), 35-52.

Lewin, K. (1997). Resolving social conflicts and field theory in social science. Washington, DC: American Psychological Association. (Original work published 1951).

Liu, B., Yang, K., \& Yu, W. (2015). Work-related stressors and health-related outcomes in public service: Examining the role of public service motivation. The American Review of Public Administration, 45(6), 653-673.

Luu, T. T. (2020). Can humble leaders nurture employee well-being? The roles of job crafting and public service motivation. Personnel Review. 50(3), 789-811.

Mahdavikhou, M., Azimian Moez, A. H., Khotanlou, M., \& Karami, G. (2014). The Impact of Moral Intelligence on Accountants' Job Performance. International Research Journal of Finance and Economics, 123, 126-146

M.Vogel, R., \& C.Feldman, D. (2009). Integrating the levels of person-environment fit: The roles of vocational fit and group fit. Journal of Vocational Behavior, 75(1), 68-81.

Ministry of Economic Affairs, Malaysia. (November 2018). 11th Malaysia Plan - Mid Term Review (2018-2020). Putrajaya: Percetakan Nasional Berhad. 
Muchinsky, P. M., \& Monahan, C. J. (1987). What is person-environment congruence? Supplementary versus complementary models of fit. Journal of Vocational Behavior, 31, 268-277.

Parliament of Malaysia. (27 March 2019). Penyata Rasmi Parlimen. Retrieved from Parlimen Malaysia: https://www.parlimen.gov.my/files/hindex/pdf/KKDR-27032019.pdf

Perry, J. L., \& Porter, L.W. (1982). Factors Affecting the Context for Motivation in Public Organizations. Academy of Management Review, 7(1), 89-98.

Perry, J. L., \& Wise, L.R. (1990). The Motivational Bases of Public Service. Public Administration Review, 50(3), $367-373$.

Perry, J. L., Hondeghem, A., \& Wise, L. R. (2010). Revisiting the Motivational Bases of Public Service: Twenty Years of Research and an Agenda for the Future. Public Administration Review, 70(5)681-690.

Potipiroon, W., \& Ford, M. T. (2017). Does public service motivation always lead to organizational commitment? Examining the moderating roles of intrinsic motivation and ethical leadership. Public Personnel Management, 46(3), 211-238.

Potipiroon, W., \& Faerman, S. (2016). What difference do ethical leaders make? Exploring the mediating role of interpersonal justice and the moderating role of public service motivation. International Public Management Journal, 19(2), 171-207.

Quratulain, S., \& Khan, A. K. (2015). Red tape, resigned satisfaction, public service motivation, and negative employee attitudes and behaviors: Testing a model of moderated mediation. Review of Public Personnel Administration, 35(4), $307-332$.

Pradhan, R. K., \& Jena, L. K. (2017). Employee performance at workplace: Conceptual model and empirical validation. Business Perspectives and Research, 5(1), 69-85.

Prendergast, C. (1999). The provision of incentives in firms. Journal of Economic Literature, 37(1), 7-63.

Rajan, M. V., \& Reichelstein, S. (2009). Objective versus subjective indicators of managerial performance. The Accounting Review, 84(1), 209-237

Ritz, A., Brewer, G. A., \& Neumann, O. (2016). Public service motivation: A systematic literature review and outlook. Public Administration Review, 76(3), 414-426.

Robinson, M. (2015). From Old Public Administration to the New Public Service Implications for Public Sector Reform in Developing Countries. Singapore: UNDP Global Centre for Public Service Excellence.

Ryu, G. (2017). Rethinking Public Service Motivation from the Perspective of Person-Environment Fit: Complementary or Supplementary Relationship? Review of Public Personnel Administration, 37(3) 351-368.

Saks, A. M., \& Ashforth, B. E. (1997). A Longitudinal Investigation of the Relationships between Job Information Sources, Applicant Perceptions of Fit, And Work Outcomes. Personnel Psychology, 50(2), 395-426.

Salas-Vallina, A., Alegre, J., \& López-Cabrales, Á. (2021). The challenge of increasing employees' well-being and performance: How human resource management practices and engaging leadership work together toward reaching this goal. Human Resource Management, 60(3), 333-347.

Sani, M. K. J. A., Endin, M. Z., Masrek, M. N., Sahid, N. Z., Baba, J., \& Kamis, Y. (2016). Integrity and job performance: The experiences of public library leaders. Journal of Southeast Asian Research, 1-15.

Singh, J., Verbeke, W. and Rhoads, G.K. (1996). Do organisational practices matter in role stress processes? A study of direct and moderating effects for marketing-oriented boundary spanners. Journal of Marketing, 60(3), 69-86

Sonnentag, S., \& Frese, M. (2002). Performance concepts and performance theory. Psychological management of individual performance, 23(1), 3-25.

Stejin, B. (2008). Person-Environment Fit And Public Service Motivation. International Public Management Journal, 11(1), $13-27$.

Su, R., Murdock, C. and Rounds, J. (2015), "Person-environment fit", in Hartung, P.J., Savickas M.L. and Walsh W.B., (Eds), APA Handbooks in Psychology. APA Handbook of Career Intervention Foundations, American Psychological Association, Washington, DC, Vol. 1, 81-98.

Udin, U. (2020). Mediating role of employee engagement in the relationship between PO fit, PJ-fit, and employee performance: a conceptual perspective for future research agenda. Journal of Research and Opinion, 7(1) 2617-2622

Uppal, N. (2021). Mediating effects of person-environment fit on the relationship between high-performance human resource practices and firm performance. International Journal of Manpower, 42(3), 356-371.

Vallerand, R. J. (1997). Toward a hierarchical model of intrinsic and extrinsic motivation. Advances in Experimental Social Psychology, 29, 271-360.

Vandenabeele, W. (2007). Toward a public administration theory of public service motivation: An institutional approach. Public management review, 9(4), 545-556.

Van Loon, N. M., Vandenabeele, W., \& Leisink, P. (2017). Clarifying the relationship between public service motivation and in-role and extra-role behaviors: The relative contributions of person-job and person-organization fit. The American Review of Public Administration, 47(6), 699-713.

Van Loon, N., Kjeldsen, A. M., Andersen, L. B., Vandenabeele, W., \& Leisink, P. (2018). Only when the societal impact potential is high? A panel study of the relationship between public service motivation and perceived performance. Review of public personnel administration, 38(2), 139-166.

Vermeeren, B., \& van Geest, D. (2012). Researchnote: Professional pride and pressures of rules in the public sector. Tijdschrift voor arbeidsvraagstukken, 28, 215-328.

Voorhees, C. M., Brady, M. K., Calantone, R., \& Ramirez, E. (2016). Discriminant validity testing in marketing: an analysis, causes for concern, and proposed remedies. Journal of the academy of marketing science, 44(1), 119-134.

Wetzels, M., Odekerken-Schröder, G., \& Van Oppen, C. (2009). Using PLS path modeling for assessing hierarchical construct models: Guidelines and empirical illustration. MIS quarterly, 33(1) 177-195.

Wright, B. E., \& Pandey, S. K. (2008). Public Service Motivation and the Assumption of Person-Organization Fit. Administration \& Society, 40(5), 502-521.

Zainal, R., Som, A. M., \& Mohamed, N. (2019). A comparative study on the implementation stage of corporate integrity in the Malaysian Public Sectors. Religación, 4(16), 123-129. 


\section{CONFLICT OF INTEREST}

The author(s), as noted, certify that they have NO affiliations with or involvement in any organisation or agency with any financial interest (such as honoraria; educational grants; participation in speakers' bureaus; membership, jobs, consultancies, stock ownership, or other equity interest; and expert testimony or patent-licensing arrangements), or nonfinancial interest (such as personal or professional relationships, affiliations, expertise or beliefs) in the subject matter or materials addressed in this manuscript.

\section{AUTHORS' BIOGRAPHY}

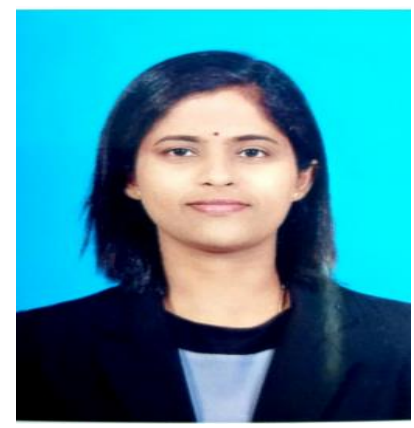

Sangeetha Tannimalay is an Administrative and Diplomatic Officer with the Government of Malaysia. She has served in several departments throughout her 12 years journey with the civil service. She completed her MBA with the Graduate School of Business, Universiti Sains Malaysia, in August 2020.

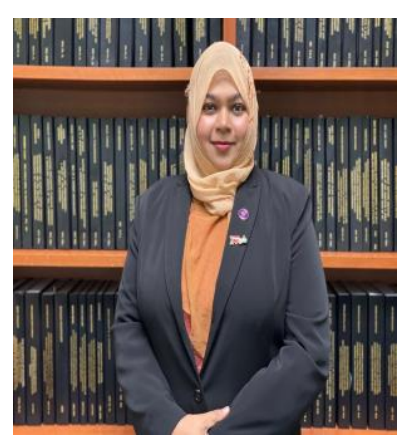

Noor Fareen Abdul Rahim is a Senior Lecturer with Graduate School of Business, Universiti Sains Malaysia (USM) since 2017. Before her career in USM, she was a banker with RHB Bank Berhad for 16 years before joining Universiti Utara Malaysia from 2015 to 2016. She has published her work in various SCOPUS and ISI journals. Her area of interest includes Organisational Behavior, Human Resource Management, Occupational Safety and Health, Internal Control System, Enterprise Risk Management, Operational Risk Management, and Technology Management. She is also involved with Executive Development Programs as a facilitator for government and private institution.

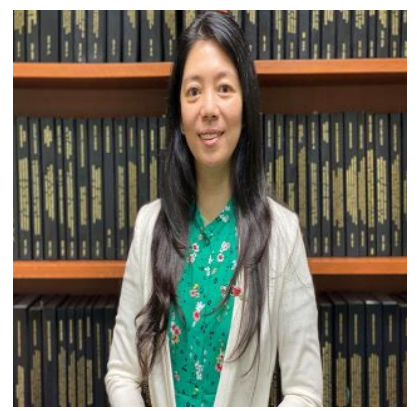

As academia, Hong Meen Chee specialises in Managerial Economics, Industrial Economics and ASEAN Business Systems. Before dedicating herself to the academic, Meenchee worked as a researcher in an international non-profit research organisation that assists in poverty and hunger reduction. From there, she gained knowledge and experiences in producing impactful research related to sustainable rural development, working with people from a multicultural background, managing cross-disciplinary and cross-institution projects. She continues her passion for knowledge sharing and research, particularly in industrial economics, sustainable consumption and production, international trade, literacy, and social well-being. She believes that research helps in her teaching and that the right knowledge is the key to success. 